\title{
The effects of two bone substitute materials in the treatment of experimentally induced mandibular defects: An experimental study
}

\section{Atalla F Rejab}

BDS, MSc. FIBMF(AssistProf)

\author{
Department of Oral and Maxillofacial Surgery
}

College of Dentistry, University of Mosul

\begin{abstract}
الخلاصة
ألأهداف: تهدف الدر اسة إلى المقارنة بين تأثير مادة العظم ألبقري منزوع البروتين, (deproteinized bovine bone) وبين مـادة العظم

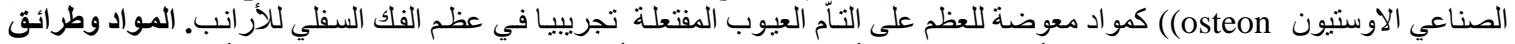

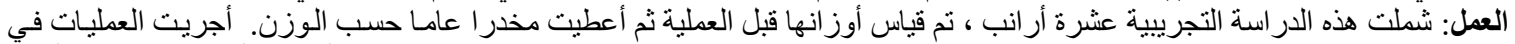

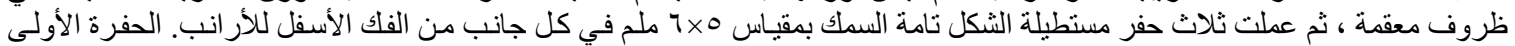

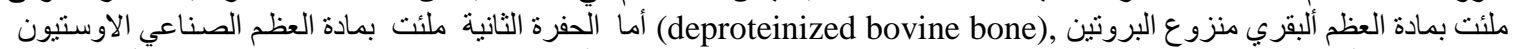
(osteon ,

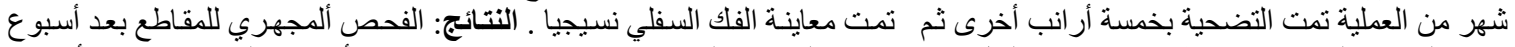

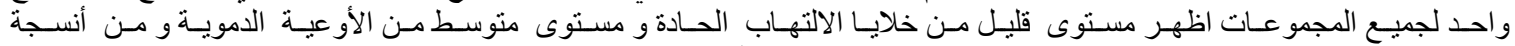

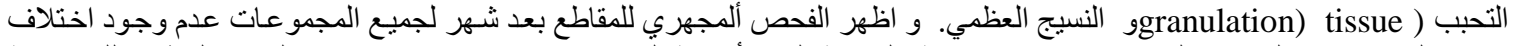

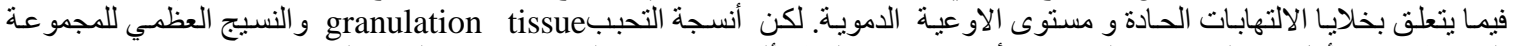

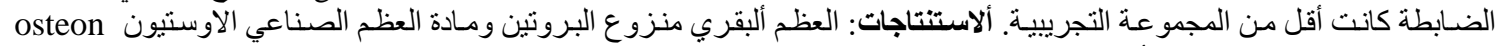

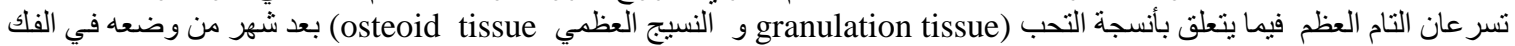
الأسفل لانى الأر انب.
\end{abstract}

\begin{abstract}
Aims: To compare between the effects of deproteinized bovine bone (DBB) and osteon in the healing of mandibular bone defects in the rabbits. Materials and Methods: This experimental study was conducted on ten rabbits at the Animal House, Dentistry college, Mosul University. The rabbits weighted between 1.5 and $2 \mathrm{~kg}$ and each rabbit was given anesthesia (10\% ketamine (40 mg/kg) and 2\% xylazine $(5 \mathrm{mg} / \mathrm{kg})$. Surgery was performed aseptically. Mandibles were exposed through a sub-mandibular incisions. Three rectangular full thickness defects $(6 \times 5 \mathrm{~mm})$ were created in each side. The first defect in each side was filled with DBB, the second defect was filled with osteon, while the third defect was left untreated to serve as a control. Five rabbits were sacrificed after one week and the other five rabbits were sacrificed after one month. The bony mandibles were immersed in $10 \%$ formalin solution and examined histologically by two histopathologists. Results: Microscopically, sections for one week of all groups showed mild degree of inflammation, moderate amount of vascularity, granulation tissue and osteoid tissue formation. Sections of one month showed no difference regarding the degree of inflammation vascularity, but the amount of granulation tissue and osteoid tissue formation in the control group were lesser than the amount seen in both experimental groups. Conclusions: DBB and osteon accelerate bone healing after month regarding the amount of granulation tissue and osteoid tissue formation.
\end{abstract}

Key words: Deproteinized bovine bone, osteon, bone substitute materials, bone healing.

Rejab AF. The effects of two bone substitute materials in the treatment of experimentally induced mandibular defects: An experimental study. Al-Rafidain Dent J. 2018, 18(1):9-20.

Received: 4/3/2014 Sent to Referees: 14/3/2014 Accepted for Publication: 26/5/2014

\section{INTRODUCTION}

Osseous defects occur as a result of trauma, prolonged edentulism, congenital anomalies, surgery, periodontal disease, and 
infection, and they often require hard and soft tissue reconstruction ${ }^{(1)}$.

Replacement of extensive local bone loss is a significant clinical challenge. There are a variety of techniques available to the surgeon to replace extensive local bone loss, each with their own advantages and disadvantages $^{(2)}$. In order to solve problems due to bone defects graft and synthetic bone substitutes have been employed for reconstruction purposes resulting in alveolar ridges with sufficient bone volume ${ }^{(3)}$.

There are four characteristics that an ideal bone graft material should exhibit which include: (i) osteointegration, the ability to chemically bond to the surface of bone without an intervening layer of fibrous tissue; (ii) osteoconduction, the ability to support the growth of bone over its surface; (iii) osteoinduction, the ability to induce differentiation of pluripotential stem cells from surrounding tissue to an osteoblastic phenotype; and (iv) osteogenesis, the formation of new bone by osteoblastic cells present within the graft material. Only autogenous bone graft satisfies all of these requirements.

Allograft is osteointegrative and osteoconductive and may exhibit osteoinductive potential, but it is not osteogenic because it contains no live cellular component. Synthetic bone graft substitutes currently possess only osteointegrative and osteoconductive properties $^{(2,3)}$.

Autogenous bone graft are considered to be the gold standard for repair of most osseous $^{(4,5)}$. However, there are limits in the amount of bone that can be harvested. Autogenous bone grafts may also increase the risk of morbidity associated with the second site surgery ${ }^{(6)}$.

Allogenic bone is harvested from an individual other than the patient, so concerns exist about the potential for disease transmission like hepatitis and human immune deficiency virus infections as well as limitation of the grafts and occasionally incomplete healing. As a result, allogenic bone is less than ideal as a grafting material $^{(4)}$. Allograft (which is harvested from one individual and transferred to another of the same species) and xenograft (from another species) usually prevent complete bone ingrowths because they are short of osteogenic cells as well as it might elicit an immune reaction to the graft. As a result, there has been recent interest in the development of new grafting materials ${ }^{(7)}$.

Deproteinized bovine bone, a biocompatible xenograft has osteoconductive action (so that it will act as a scaffold for the migration of osteoprogenator cells and the formation of new bone), and its porous surface is subject to vascularisation and permeation with collagen fibres, which leads to osteogenesis. It resorbs itself slowly, being integrated in 
the process of natural remodelling ${ }^{(3)}$.

This study was designed to assess the effects of two bone substitute materials consisting of deproteinized bovine bone and osteon on acceleration of bone healing of surgically created defects.

\section{MATERIALS AND METHODS}

Ten white albino male rabbits weighing between 1.5 and $2 \mathrm{~kg}$ were included in this experimental study which was conducted on ten rabbits at the Animal House, Dentistry college, Mosul University. The study started at June 2013 to October 2013. Three defects were created in each animal. The first defects considered as group I (A negative control group in which the defects were not filled with bone substitute material), the second defects considered group II (the second defects which were filled with deproteinized bovine bone granules), and the third defects considered group III (The third defects which were filled with osteon granules.

The animals were kept outdoor in cages and fed green leaves, fruits, and vegetables. They all seemed to have good health throughout the period of the study. The study protocol was approved by the Scientific Committee of Oral and Maxillofacial Surgery Department, Dentistry college, Mosul University

The rabbits weighted between 1.5 and 2 $\mathrm{kg}$. Each animal was anaesthetized with intramuscular injection of $10 \%$ ketamine (40 $\mathrm{mg} / \mathrm{kg}$ ) (ELSaad, Aleppo, Syria) and 2\% xylazine $(5 \mathrm{mg} / \mathrm{kg})$ (Inferchemie, Holland). Then its fur was removed using electrical clipper from the lower border of the mandible .The mandible of the animals was scrubbed thoroughly with butadiene. Surgery was performed under aseptic conditions. The left and right mandiblular bones were exposed through a submandiblular incision. Three rectangular full thickness defects $(6 \times 5 \mathrm{~mm})$ were created in each side using a surgical bur under copious irrigation with normal saline. The first defect (group I) in each side was left untreated to serve as a control. The second defect in each side (group II) was filled with deproteinized bovine bone granules (Braumer, Brazil). While the third defect in each side(group III) was filled with osteon granules (Dentium, Korea). The woundS were then closed with $3 / 0$ black silk suture. The rabbits were given intra-muscular injections of oxy tetracycline hydrochloride calculated at $30 \mathrm{mg} / \mathrm{kg}$ body weight, immediately after surgery. All animals recovered from anesthesia without complications. Five rabbits were sacrificed one week after surgery and the other five rabbits were sacrificed one month after surgery. The bony mandibles were dissected out from the heads and immediately immersed in $10 \%$ formalin solution for fixation, for three days, dehydrated in 
graded alcohol and embedded in paraffin.

Five-micrometer decalcified sections were prepared and stained with haematoxylin and eosin and examined for histological analyses.

\section{RESULTS}

\section{Histopathological analysis:}

The slides available in this study for histological examination comprised 60 slides, divided into two time groups (one week and one month), control and two study defect slides.

Histopathological evaluation of specimens from control and experimental groups were done with particular emphasis on the degree of inflammatory process, vascularity, amount of granulation tissue and osteoid formation.

\section{Results at the end of the first week:} (Tables1, 2)

Table (1): Paired T-test comparing granulation tissue and osteoid tissue at two periods for all groups

\begin{tabular}{|c|c|c|c|c|c|c|c|c|}
\hline \multirow[b]{3}{*}{$\begin{array}{l}\text { Granulation tissue } \\
1 \text { week - } \\
\text { Granulation tissue } \\
1 \text { month }\end{array}$} & \multirow[b]{2}{*}{ Mean } & \multirow{2}{*}{$\begin{array}{c}\text { Std. } \\
\text { Deviation }\end{array}$} & \multirow{2}{*}{$\begin{array}{l}\text { Std. } \\
\text { Error } \\
\text { Mean }\end{array}$} & \multicolumn{2}{|c|}{$\begin{array}{l}95 \% \text { Confidence Interval of } \\
\text { the Difference }\end{array}$} & \multirow[b]{2}{*}{$\mathrm{t}$} & \multirow[b]{2}{*}{$\mathrm{df}$} & \multirow[b]{2}{*}{ Sig. (2-tailed) } \\
\hline & & & & Lower & Upper & & & \\
\hline & 5.294 & 10.073 & 2.443 & .115 & 10.473 & 2.167 & 16 & $.046^{*}$ \\
\hline $\begin{array}{l}\text { Ostioid tissue } 1 \\
\text { week - Ostioid } \\
\text { tissue } 1 \text { month }\end{array}$ & $4.41 \overline{2}^{-}$ & 14.018 & 3.400 & -11.619 & 2.796 & -1.298 & 16 & .213 \\
\hline
\end{tabular}

* mean significant difference at $p>0.05$

Table (2): ANOVA test comparing granulation and osteoid tissue for all groups at different periods

\begin{tabular}{|c|c|c|c|c|c|c|}
\hline \multirow{5}{*}{$\begin{array}{l}\text { Granulation tissue } 1 \\
\text { week }\end{array}$} & \multirow{2}{*}{\multicolumn{2}{|c|}{ Sum of Squares }} & \multicolumn{3}{|c|}{ Mean } & \multirow[b]{2}{*}{ Sig. } \\
\hline & & & Df & Square & $\mathrm{F}$ & \\
\hline & Between Groups & 408.125 & 2 & 204.063 & 8.953 & $.003 *$ \\
\hline & Within Groups & 341.875 & 15 & 22.792 & & \\
\hline & Total & 750.000 & 17 & & & \\
\hline \multirow{3}{*}{ Osteoid tissue 1 week } & Between Groups & 3814.236 & 2 & 1907.118 & 35.899 & $.000 *$ \\
\hline & Within Groups & 796.875 & 15 & 53.125 & & \\
\hline & Total & 4611.111 & 17 & & & \\
\hline Granulation tissue 1 & Between Groups & 22.254 & 2 & 11.127 & .226 & .799 \\
\hline \multirow{2}{*}{ month } & Within Groups & 1081.746 & 22 & 49.170 & & \\
\hline & Total & 1104.000 & 24 & & & \\
\hline \multirow[t]{3}{*}{ Osteoid tissue 1 month } & Between Groups & 1790.032 & 2 & 895.016 & 8.365 & $.002 *$ \\
\hline & Within Groups & 2353.968 & 22 & 106.999 & & \\
\hline & Total & 4144.000 & 24 & & & \\
\hline
\end{tabular}

* mean significant difference at $p>0.05$ 
I- Group I (control group): A negative control group in which the defects were not filled with bone substitute material 1.Inflammatory cells: Microscopic examination of the sections of the control group after one week showed mild inflammatory cell infiltration.

2.Vascularity: Microscopic examination of the sections of the control group after one week of the experiment showed moderate amount of vascularity.

3.Granulation tissue: Moderate amount of granulation tissue was shown in this group which was the same in all the groups under microscopic examination.

4.Osteoid tissue formation: Microscopic examination of the sections of the control group after one week regarding osteoid tissue formation showed no significant differences from other experimental groups.

II- (Group II): the second defects which were filled with deproteinized bovine bone granules.

1.Inflammatory cells: Showed mild inflammatory cell infiltration.

2.Vascularity: Microscopic examination of the sections showed also moderate amount of vascularity.

3.Granulation tissue: Moderate amount of granulation tissue was shown in this group under microscopic examination.

4.Osteoid tissue formation: Microscopic examination of the sections showed no significant differences from other groups (Figure 1).

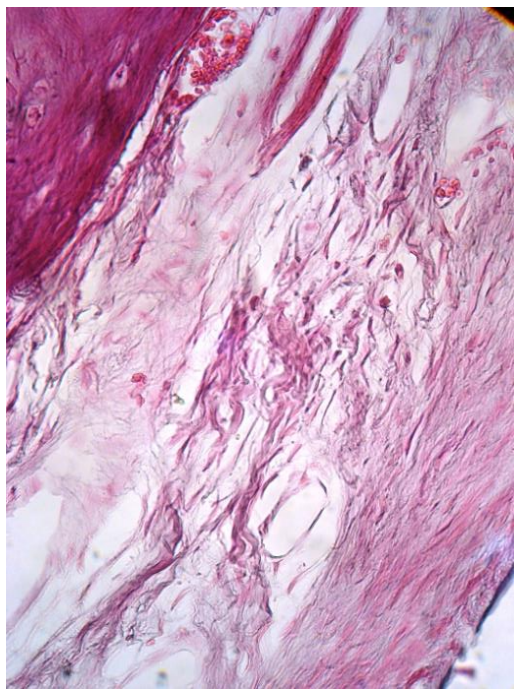

Figure (1): Cross section of defect (group II) at 7 days. fibrous tissue consisting of fibroblasts, collagen fibers, newly formed capillaries, and bundles of collagen fibers. 
III- (Group III): The third defects which were filled with osteon granules.

1. Inflammatory cells: Microscopic examination showed also mild inflammatory cell infiltration.

2. Vascularity: Microscopic examination of the sections showed moderate amount of vascularity.
3. Granulation tissue: Moderate amount of granulation tissue was shown under microscopic examination.

4. Osteoid tissue formation: Microscopic examination showed no significant differences from other experimental groups (Figure 2).

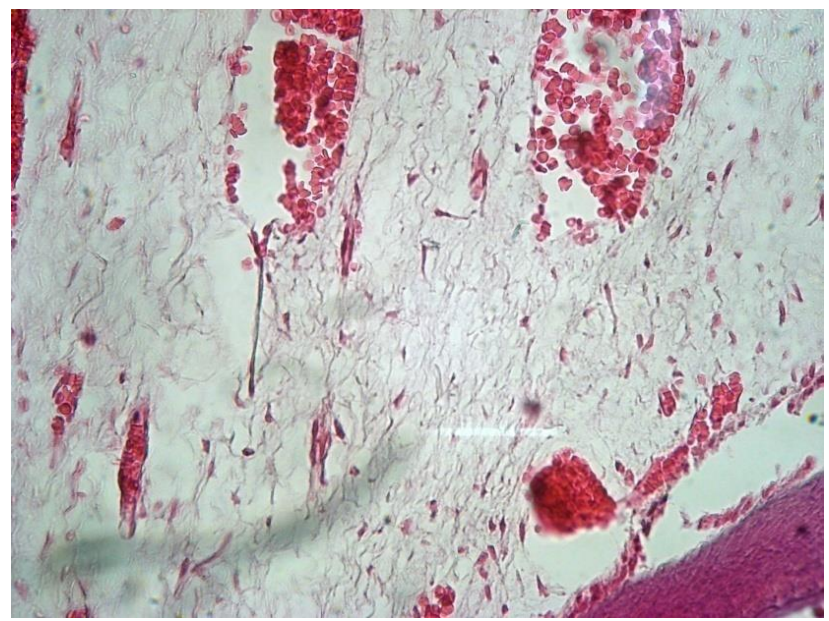

Figure (2): Cross section of defect (group III) at 7 days. Note the presence of loose fibrous tissue with congested blood vessels.

Results after one month: (Table 1and 2)

I- Group I (control group):

1.Inflammatory cells: Microscopic examination of the sections from the control group after one month showed very mild inflammatory cell infiltration.

2.Vascularity: Microscopic examination of the sections of the control group after one month of the experiment showed moderate amount of vascularity.
3.Granulation tissue: Moderate amount of granulation tissue was shown under microscopic examination, but the amount was lesser than the amount in both group II and group III.

4.Osteoid tissue formation: Microscopic examination of the sections of group I (the control group) after one month showed mild amount of osteoid tissue formation (Figure $3)$. 


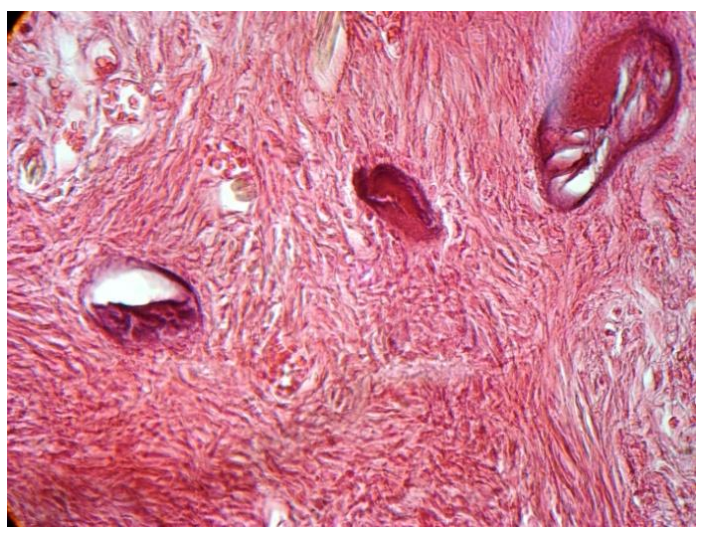

Figure (3 ): Cross section of control defect (group I) at 1 month. Thick randomly arranged bundles consisting of fibrocytes and collagen fibers surrounding islets of old bone (arrow).

II- (Group II): A study group in which the second defects were filled with deproteinized bovine bone granules.

\section{Inflammatory cells: Microscopic} examination of the sections taken from the second defects of the experimental group after one month of the application of deproteinized bovine bone granules (Braumer, Brazil) showed very mild inflammatory cell infiltration.

2. Vascularity: Microscopic examination of the sections taken from the second defects of the experimental group after one month of the application filled with osteon granules (Dentium, Korea) in the osseous defects showed moderate amount of vascularity which was more than the vascularity in the control group.

3. Granulation tissue: Moderate amount of granulation tissue was shown in this group under microscopic examination which was more than that seen in the control group.

4. Osteoid tissue formation: Microscopic examination of the sections of the group II after one month regarding osteoid tissue formation showed moderate amount of osteoid tissue formation (Figure 4). 


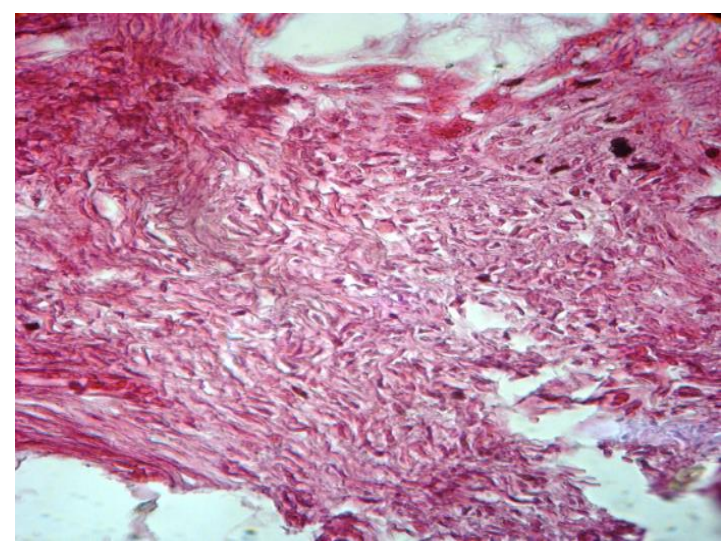

Figure (4): Test specimen (group II) after one month. Mature fibrous tissue with areas of ossification can be visualized (arrow).

III- (Group III): A study group in which the third defects were filled with osteon granules.

1. Inflammatory cells: Microscopic examination of the sections taken from the third defects of the experimental group after one month of the application of osteon granules showed also very mild inflammatory cell infiltration.

2. Vascularity: Microscopic examination of the sections of the control group after one month of the experiment showed moderate amount of vascularity which was more than the vascularity in the control group.

3. Granulation tissue: Moderate amount of granulation tissue was shown under microscopic examination which was more than that seen in the control group.

4. Osteoid tissue formation: Microscopic examination of the sections of the control group after one week regarding osteoid tissue formation showed moderate amount of osteoid tissue formation (Figure 5).

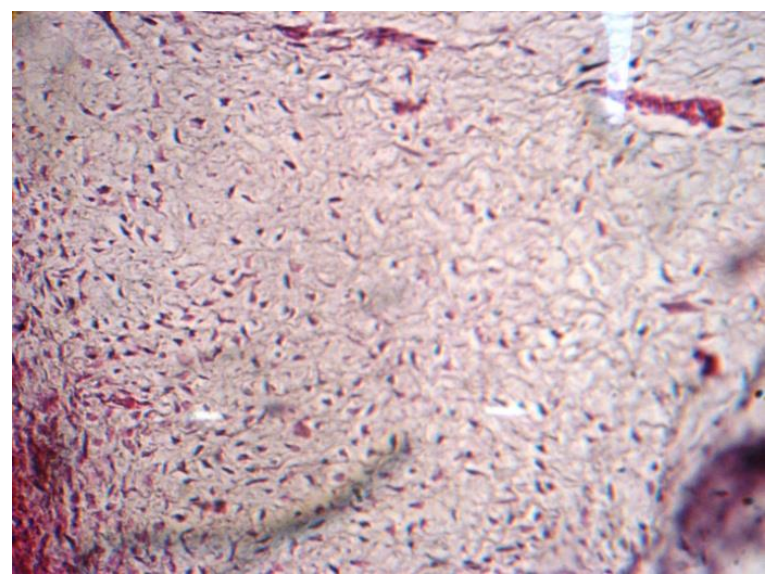

Figure (5): Test specimen (group III) after one month. Cartilage cells are filling the defects. 


\section{DISCUSSION}

In this study osteon bone substitute material was used. This material is composed from HA (70\%) and $\beta$ TCP $(30 \%)$. Beta-tricalcium phosphate $(\beta$ TCP) has been used in many experimental and clinical studies. It is a bone substitute that is osteoconductive and biodegradable ${ }^{(8)}$. It can assist in the processes of bone regeneration. It resorbs after a certain period of time in situ and is then replaced by newly formed bone ${ }^{(6)}$. TCP considered to be biocompatible(not stimulating inflammatory or foreign body giant cell activity). This is mainly because TCP is composed of calcium and phosphate ions, which are the most commonly found elements in bone ${ }^{(9)}$.

Hydroxyapatite (HA) can be machined to many shapes or consistencies and has several potential clinical applications including the filling of bony defects, the retention of alveolar ridge form following tooth extraction and as a bone expander when combined with autogenous bone during ridge augmentation and sinus grafting procedures (10) Calciumhydroxy apatite/tricalciumphosphate when used together in certain percentages provide a structure or scaffold which can have a close interface with adjacent bone and have a limited application in the treatment of loadbearing segmental bone defects but did not fail at the early stages of implantation ${ }^{(11)}$. In this study osteon was used which contain HA and $\beta$-TCP.

Like HA, TCP is bioabsorbable and biocompatible. The chemical composition and crystallinity of the material are similar to those of the mineral phase of bone. It exists in either $\alpha$ or $\beta$-crystalline forms. The rate of biodegradation is higher when compared with HA. However, the replacement of $\beta$-TCP by bone does not occur in an equitable way. That is, there is always less bone volume produced than the volume of $\beta$-TCP reabsorbed. For this reason the clinical use of $\beta$-TCP has been as an adjunctive with other less reabsorbable bone graft substitutes ${ }^{(2)}$. As is the case in this study in which $\beta$-TCP was used with HA to extend the resorption rate of $\beta$-TCP. Some problems have been reported by the use of non or slowly absorbed osteoconductive HA, which is commonly used bone substitute, these problems may include prevention of the establishment of the blood vessels network when the cavity is filled with excessively dense particles, and normal bone marrow is not formed during bone remodeling. HA and $\beta$-TCP are most widely used. They allow osteogenesis to occur and form tight bonds with host bone tissues $^{(12)}$. Althoughd this study showed an a ccelerated bone healing using osteon, this is do not agree with a study conducted by 
$\operatorname{kim}^{(13)}$ who found no beneficial effect of osteon in sinus bone grafting. The same results obtained by Abdo and $\mathrm{h}^{(14)}$ who also found that using osteon alone is not an effective therapy for treatment of bone defects in rabbits.

DBB is a biocompatible xenograft which has been used in different osseous deficiencies. This material is screened for a total deproteinization process to eliminate any graft rejection elicited by the protein matrix. Chemically and physically, the particles are identical to human mineral matrix, and their inner macropores are similar in size to natural cancellous bone. This kind of framework probably guides direct apposition of osteoid in regenerative procedures. Because this mineral is prepared under a low-heat extraction process, its porosity shape remains intact, thus contributing to the initial blood clot stability at the surgical site. DBB has been shown to be well tolerated and integrated by the host tissues. It is biocompatible, amalgamate, and incorporates well within the newly formed regenerated hard tissue, with almost no clinical postoperative complications. Clinically, the presence of DBB particles does not interfere with the wound healing process. This observation was supported by Hämmerle et al, who added that induction of newly formed bone was noted $^{(15)}$.
Kling et al found that DBB particles were capable of providing a scaffold for new bone formation ${ }^{(16)}$. Andreas et at concluded that grafting of DBB as an adjunct to guided tissue regeneration arrests bone formation ${ }^{(17)}$. In the current study DBB was used without guided tissue regeneration.

Paknejad et al., (2007) proposed that implantation of a deproteinized natural bovine cancellous bone mineral, may accelerate bone regeneration more effectively than a mixture of synthetic hydroxyl apatite, equine type I collagen, and chondroitin sulfate ${ }^{(3)}$. In the present study both osteon and DBP accelerated bone to the same degree.

The ideal bone substitutes should have biocompatibility, excellent osteoconductive properties and appropriate strength and they should be able to form a suitable shape easily and to ultimately replace the bone completely within a short period ${ }^{(18)}$. Both the two bone substitutes used in this study elicited a mild inflammatory cell infiltration indicating that they are both biocompatible. DBP and osteon used in the present study were in a granular form and therefore they can fill in the damaged area in any form.

In this study it has been found that both osteon and DBB were useful in accelerating bone healing in rabbits and there were no significant difference between the amount of granulation tissue and osteoid tissue 
formation as they both increased the amount of granulation tissue and osteoid tissue formation which were more than the granulation tissue and osteoid tissue formation found in the control group at one month periods which is especially important in dental implants and in oral and maxillofacial reconstruction, for both the functional and psychological aspect.

\section{CONCLUSIONS}

In this study it has been found that both osteon and deproteinized bovine bone when they were used as bone substitutes filling a bony cavity in rabbits were useful in accelerating bone healing at one month intervals with less degree of inflammatory cell infiltration, and increased amount of granulation tissue and osteoid tissue formation.

\section{REFERENCES}

1. Pikos M A. Mandibular Block Autografts for Alveolar Ridge Augmentation. Atlas Oral Maxillofacial Surg Clin $N$ Am. 2005;13:91-107

2. Moore W R., Graves S E. and Bain G I. Synthetic bone graft substitutes. ANZ $J$. Surg. 2001; 71: 354-361.

3. Paknejad M, Rokin AR, Eslami B, Afzaifar $\mathrm{R}$ and Safiri A. Evaluation of three bone substitute material in the treatment of experimentally induced defects in rabbit calvaria. Journal of dentistry, Tehran
University of Medical Sciences.2007; 4(4):171-176.

4. Clokie G M L and Sandor G K B . Reconstruction of 10 major Mandibular Defects Using Bioimplants Containing BMP. JCDA.2008;74(1): 67-72.

5. Yamauchi K, takahashiT, Funaki K, Miyamoto I, and Yamashita Y. Implant Placement for Periosteal Expansion osteogenesis using B-Tricalcium phosphate block: An experimental study in dogs . Oral and maxillofacial implant. 2009;108 (6): 861-865.

6. Horowitz RA, Mazor Z, Foitzik C, Prasad $\mathrm{H}$, Rohrer $\mathrm{M}$ and Palti A. $\beta$ - tricalcium phosphate as bone substitute material: properties and clinical applications. the international journal of dental implants and biomaterials.2009;1(2):1-11.

7. Vuola J . Natural coral and hydroxyapatites as bone substitutes. Department of plastic surgery Helsinki, Helsinki university central hospital.2001, cited by Al-attar BH bone regeneration using hydroxyapplatite granules with and without guioded bone regeneration membrane. M.ScThesis ,University of Mosul , College of Dentistry.2011.

8. Mauri M, Sato S, Koshi R, Yokoyama K, Ikeda K, Narukawa M, Takayama T, Yoshinuma $\mathrm{N}$ and Ito $\mathrm{K}$. effects of the enamel matrix derivative and $\mathrm{B}-\mathrm{TCP}$ on bone augmentation within a titanium cap 
in rabbit calvarium. Journal of Oral Science.2005;47(4): 209-217.

9. Podaropoulos L, Veis A, Papadimitriou S, Alexandridis $\mathrm{C}$ and Kalyvas D. Bone regeneration using B-TCP in a calcium sulphate matrix. Journal of oral implantology,2009; 34(1): 28-36.

10. Sàndor G.K.B., Lindholm T.C. and Clokie C.M.L.Bone Regeneration of the Craniomaxillofacial and Dento-alveolar Skeletons in the Framework of Tissue Engineering. Topics in Tissue Engineering 2003. Eds. N. Ashammakhi \& P. Ferretti 2003 University of Oulu.

11. Nandi K, Roy S , Mukherjee P , B Kundu, De D K \& Basu D. Orthopaedic applications of bone graft \& graft substitutes: a review. Indian J Med Res. 2010;132: 15-30S.

12. Hassna $R$ and M. Zhang. Biphasic calcium phosphate nanocomposite porous scaffolds for load-bearing bone tissue engineering. Biomaterials. 2004;25:5171-5180.

13. Kim YK, Yun PY, Lim SC, Kim SG, Lee HJ, Ong JL. Clinical evaluations of Osteon as a new alloplastic material in sinus bone grafting and its effect on bone healing. J Biomed. Mat. Res. B Appl Biomater; 2008; 86:270-7.

14. Abdo FS. Hasouni MK. Effects of Combination of Platelet Rich Plasma and OSTEON Material in Rabbits Bone Healing
(A comparative study) Al-Rafidain Dent $J$. 2014; 14(1):90-100.

15.Artzi Z, Nemcovsky C E, Tal H. Efficacy of Porous Bovine Bone Mineral in Various Types of Osseous Deficiencies: Clinical Observations and Literature Review., Volume 21, Number 4, 2001. COPYRIGHT 2001 BY QUINTESSENCE PUBLISHING CO, INC.

16.Klinge B, Alberius P, Isaksson S, Jonsson J. Osseous response to implanted natural bone mineral and synthetic hydroxylapatite ceramic in the repair of experimental skull bone defects. J Oral Maxillofac Surg. 1992 Mar;50(3):241-9.

17. Andreas S, Lambros K, Jens $\mathrm{R}$. Deproteinized bovine bone (Bio-Oss ${ }^{\circledR}$ ) and bioactive glass $\left(\right.$ Biogran $\left.^{\circledR}\right)$ arrest bone formation when used as an adjunct to guided tissue regeneration (GTR) An experimental study in the rat. Journal of Clinical Periodontology . 2003;30: 636-643.

18. Masgo H, Shibya Y, Munemoto S, Takeuchi J, Umeda M, Komori T, and Kuboki Y. Alveolar Ridge augmentation using various bone substitutes-A web form of titanium fibers promotes rapid bone development. Kobe J. Med Sci. 2007; 53(5):257-263. 